\title{
Product Innovation of Private Health Insurers \\ IN SOUTH AFRICA AND THE IMPACT OF ENTREPRENEURIAL ORIENTATION
}

\author{
Boris Urban and Milton Streak \\ Wits Business School, University of the Witwatersrand
}

Accepted: March 2013

\begin{abstract}
Recognising that health insurer product innovation plays a critical role in aligning incentives among all stakeholders in the healthcare value chain, this study investigates the relationship between the level of health insurer product innovation and entrepreneurial orientation (EO). Taking cognisance of the importance of external collaboration between health insurers and healthcare service providers, the study is able to diagnose perceptions of strategic regulatory factors and their impact on levels of EO. The focus of the study is on the demand (financing) and supply (healthcare delivery) structures of the healthcare value chain, incorporating health insurers, health insurer administrators and healthcare service providers. A conceptual model is formulated on the basis of literature and tested using confirmatory factor analysis. The results indicate that EO at organisational level is a strong predictor of health insurer product innovation and that external collaboration between health insurers and healthcare service providers is a weak predictor of health insurer product innovation. Practical implications are that both the supply and demand side structures indicate that the restructuring of relationships between health insurers and healthcare service providers is a necessary driver for collaboration in terms of health insurer product innovation progress and success. Healthcare executives need to work with, and actively lobby regulators to ignite both demand and supply side innovation activities in the healthcare value chain of the private healthcare industry of South Africa.
\end{abstract}

Key words: product innovation, regulation, external collaboration, entrepreneurial orientation, health insurers, corporate entrepreneurship, healthcare industry

JEL: M19

\section{1}

\section{Introduction}

In the context of healthcare inequalities and a struggling and underfunded public healthcare system in South Africa, the South African private healthcare industry is viewed as a national asset. The private healthcare industry in South Africa is complex and requires expertise and innovativeness to ensure the financial sustainability of private health insurers and the industry as a whole. The private healthcare insurance market in South Africa is voluntary and accounts for 60 per cent of total healthcare expenditure, but it serves only 16 per cent of the South African population - those with higher incomes (Centre for Development and Enterprise, 2011; Council for Medical Schemes, 2010/11). Approximately five-million formally employed people in South Africa are not yet insured for healthcare (McLeod \& Grobler, 2010). It is essential that they enter the private healthcare insurance market to ensure growth and future sustainability of the private healthcare industry. This could align the incentives of stakeholders (demand and supply side structures) in the private healthcare value chain, and thus could create the necessary access to private healthcare cover for the uninsured.

This research builds on the existing framework by Guth and Ginsberg (1990) which integrates corporate entrepreneurship into the strategic management of a company (Morris, Kuratko \& Covin, 2008). Innovation throughout the entire healthcare value chain is required to drive sound healthcare reform ensuring sustainable, cost-effective quality healthcare delivery in the private healthcare industry. The focus of the study was on the demand (financing) and supply (healthcare delivery) structures of the 
healthcare value chain, incorporating health insurers, health insurer administrators and healthcare service providers. According to Porter and Teisberg (2006), health insurer product innovation, focusing on positive sum competition on results, plays a critical role in aligning incentives among all stakeholders in the healthcare value chain. External collaboration among health insurers, health insurer administrators and healthcare service providers - focusing on innovation and building of systems that promote health and treat illness is essential in creating future sustainable healthcare delivery systems (Mintzberg, 2011).

The aims of the study were to investigate firm-level entrepreneurial orientation of health insurers, health insurer administrators and healthcare service providers in South Africa and its relationship to health insurer product innovation. Furthermore, the research study aimed to investigate the extent to which health insurers and healthcare service providers collaborate in designing and implementing new innovative health insurer products. The study further investigated the moderating effect of the presence of perceived strategic regulatory factors necessary for encouraging health insurer product innovation in the private healthcare industry in South Africa.

The study starts by briefly reviewing past research on EO and related constructs in order to operationalize these constructs and design suitable measures. A conceptual model is formulated and hypotheses are developed to test linkages between the variables under study. The results are scrutinized in terms of previous theory and contextualised from a private health care management perspective. Both theoretical and practical implications are drawn from the empirical evidence, and recommendations for future research are made.

\section{2}

\section{Entrepreneurial orientation (EO)}

Extensive research exists on the EO construct which reflects how a firm operates rather than what it does (Lumpkin \& Dess, 1996; Li, Huang \& Tsai, 2009). The concept of EO incorporates organisational-level processes, practices and decision-making styles of innovative organisations (Lumpkin \& Dess,
1996; Urban \& Barreira, 2010). The strength of an organisation's EO can have a positive effect on performance (Green, Covin \& Slevin, 2008; Morris \& Sexton, 1996; Wiklund \& Shepherd, 2005; Zahra \& Covin, 1995). EO is also an important predictor of firm growth: firms that nurture structures and values conducive to intrapreneurial activities are more likely to grow than firms lacking in such characteristics (Antoncic \& Hisrich, 2001; Dess, Ireland, Zahra, Floyd, Janney \& Lane, 2003; Urban, 2008). According to Li et al. (2009) in order for organisations to respond to the dynamic and competitive environment in which they operate, they need to transfer EO consistently into feasible strategic activities that fulfil the organisations' objectives and achieve superior performance.

The literature confirms three dimensions that characterise an entrepreneurial orientation: innovativeness, risk taking and proactiveness (Morris et al., 2008; Urban \& Barreira, 2010). According to Dess and Lumpkin (2005), prior research has explored the direct relationship between EO and performance (Rauch, Wiklund, Lumpkin \& Freeze, 2004) as well as the sustainability of that relationship (Wiklund, 1999). Dess and Lumpkin (2005) also indicate that the EO-performance relationship is dependent on the fit between EO and factors like environment, structure and strategy (Dess, Lumpkin \& Covin, 1997). Wiklund and Shepherd (2003) have suggested that EO acts as a moderator and found that the relationship between knowledge-based resources and performance was stronger in organisations with higher levels of EO (Dess \& Lumpkin, 2005). Furthermore, Dess and Lumpkin (2005) indicate that exploring relationships among the individual dimensions of EO and performance is superior to considering EO as a onedimensional construct and that the individual dimensions of EO were more robust predictors of organisational growth than a summated onedimensional EO construct. According to Urban and Barreira (2010) the EO concept is best understood as a complex mix of personal and situational factors, and in addition to individual and organisational differences, forces operating within other, larger cultural contexts also determine levels of EO (Aloulou \& Foyolle, 2005). Therefore, organisations with EO typically 
out-perform other similar organisational types with less EO, especially in volatile times (Knight, 1997; Urban \& Barreira, 2010).

Previous research demonstrates a strong link between EO and new product development improvement (Drucker, 1979; Lumpkin \& Dess, 1996; Li, Liu \& Zhao, 2006). According to $\mathrm{Li}$ et al. (2009), the resource advantage theory stipulates that innovative competencies may be a source of competitive advantage because they are deeply rooted in the context of the organisation and cannot be explicitly articulated or imitated (Barney, 1991; Nonaka, 1994; Hunt \& Arnett, 2006; Hunt \& Morgan, 1996). Other researchers suggest that by increasing commitment to innovative products and processes, organisations can renew their operations in the marketplace and improve their profitability (Li et al., 2009; Lumpkin \& Dess, 1996; Miller, 1983; Zahra \& Garvis, 2000). Similarly, Li et al. (2006), develop a systemic conceptual model to describe the relationship among organisational orientation, internal control systems and new product development. Recognising that EO includes major processes, innovations and different types of venture creation initiatives, constructs related to entrepreneurship within organisations and their ability to transform organisations though strategic renewal (Guth \& Ginsberg, 1990; Morris et al., 2008), are examined in the next section.

\section{3}

\section{Corporate entrepreneurship (CE) and entrepreneurial strategy}

According to Morris et al. (2008), CE is a term used to describe entrepreneurial behaviour inside established medium and large organisations. Other terms used interchangeably with CE include intrapreneurship, corporate venturing and organisational entrepreneurship (Morris et al., 2008). At the core of these terms is innovation. Innovation is concerned with introducing something new to the market place and corporate venturing is concerned with entrepreneurial efforts that lead to the creation of new business ventures within corporate organisations (Morris et al., 2008).

According to Ireland, Covin and Kuratko (2009) entrepreneurial strategy is a core construct within the $\mathrm{CE}$ literature and a specific manifestation of firm-level entrepreneurship. Ireland et al. (2009) suggest that the organisational-level outcomes of CE strategy are competitive capability and strategic repositioning. Further research (Covin, Ireland \& Kuratko, 2003; Ireland et al., 2009) demonstrates that exploiting entrepreneurial opportunities enables organisations to both strengthen existing competitive capabilities and build new competitive capabilities. Competitive capability, as per Ireland et al. (2009), is the capacity of firms to create and sustain economically viable industry positions (Nelson, 1991; Teece, Pisano \& Shuen, 1997). According to Ireland et al. (2009), strategic repositioning can alter relationships among competitors in an industry, by strategically locating the organisation within a newly defined competitive space (Ireland et al., 2009; Stopford \& BadenFuller, 1994). Having conceptualised the constructs under scrutiny, the study is now contextualised in the South African private healthcare industry.

\section{4}

\section{The private healthcare industry in South Africa}

According to Monitor Group (2008), the South African private healthcare system is ranked high on the performance versus cost rankings and compares more favourably with health systems in developed economies. Conversely, the public healthcare system in South Africa is ranked low in terms of performance versus cost. The cost ranking of the South African private healthcare system compared to performance is however out of line and it is therefore imperative that costs and access are more aggressively managed through innovation in the healthcare value chain. According to the Centre for Development and Enterprise (2011), the average cost of belonging to a private health insurer has increased fivefold in real terms since 1980. Innovation is critical if health insurers want to win subscribers and stay ahead of the competition (Porter \& Teisberg, 2006). Additionally, health insurers view external collaboration between health insurers, health insurer administrators and healthcare service providers as a major driving factor of product innovation and healthcare 
efficiencies (Porter \& Teisberg, 2006) in the healthcare system.

Acknowledging the healthcare landscape in South Africa, it is imperative to investigate whether health insurers, health insurer administrators and healthcare service providers are able to act entrepreneurially in terms of product innovation. To this effect, the firmlevel EO of health insurers, health insurer administrators and healthcare service providers in the South African private healthcare industry, are specifically investigated.

\subsection{Health insurer product innovation}

Damanpour and Wischnevsky (2006) suggest a method to address the different scopes of newness in the innovation literature. They differentiate between the generation and the adoption of innovations. The generation of innovation refers to situations where a firm internally generates a product, process or technology that was previously unknown to the market in which the firm operates. The adoption of innovation, on the other hand, refers to the assimilation of knowledge and technologies, that have been developed elsewhere and that are new to the organisation only (Pérez-Luño, Wiklund \& Cabrera, 2011).

Innovation output has been associated with organisational performance (Rosenbusch, Brinkman \& Bausch, 2011). According to Wiklund (1999) and Soininen, Martikainen, Puumalainen and Kylaheiko, (2011) innovation keeps organisations ahead of their competitors, thereby gaining competitive advantage and leading to improved financial results. Product innovation translates into superior sales and growth rates, and is a more complex process with multiple inputs requiring more advanced knowledge contributions and absorptive capacity (Goedhuys \& Veugelers, 2011). Pérez-Luño et al. (2011) classify innovation output as the proportion of total innovation output (number of innovations that organisations produce) that falls within each of the two categories: innovation generation and innovation adoption.

\subsection{External collaboration between health insurers and healthcare service providers}

Zillich, Douchette, Carter and Kreiter (2005) define collaboration among healthcare pro- fessionals as a joint communication and decision-making process with the goal of satisfying the patient's wellness and illness needs, while respecting the unique qualities and abilities of each professional. This definition is also applicable in terms of the collaboration between healthcare service providers and health insurers and/or health insurer administrators in developing and implementing new innovative health insurer products. Discussions around healthcare reform rarely focus on health outcomes, instead the emphasis is on cost, cost-shifting and access (Teisberg \& Wallace, 2009). In healthcare, patient outcomes define quality and quality can be enhanced by preventing errors, reducing waste and improving coordination (Teisberg \& Wallace, 2009). Each of these changes creates better experiences for patients and brings down costs (Teisberg \& Wallace, 2009).

According to Porter and Teisberg (2006), health insurers have a unique and essential role in value-based competition and innovation in healthcare. They emphasise that health insurers must rethink and reorient their whole approach toward value-based competition. Health insurers must become health organisations dedicated to patient and physician information, support and service, not just organisations for administrative, auditing and financial services (Porter \& Teisberg, 2006). Health insurers must therefore move from being adversaries to true partners in value creation for patients (Porter \& Teisberg, 2006).

It is critical to restructure the health insurerhealthcare service provider relationship so that the adversarial mind-set between health insurers and healthcare service providers makes way for a spirit of collaboration in terms of creating value for patients (Porter \& Teisberg, 2006). When health insurers and healthcare service providers join forces around value and health results, efficiency improves exponentially and administrative costs fall (Porter \& Teisberg, 2006).

According to Vanvactor (2011), external collaboration and cooperation is critical in today's business environment. As related by Kouzes and Posner (2007), and Vanvactor (2011) collaboration is so critical to success that every significant relationship should be treated as if it is a lifelong endeavour. Healthcare 
management is an evolutionary process and the relationships established among multifaceted partners can produce dynamic effects on an organisation's environment (Vanvactor, 2011).

\subsection{Healthcare regulation}

According to Dassler (2006) traditionally, two theories of regulations have emerged, first the concept of 'regulatory intervention' or, in different terms, the way regulators conduct market intervention and distinguish between market-driven and non-market-driven approaches. Second, in the context of 'regulatory governance', Majone (1996) identifies a substantive and proceduralist model. This study however, focuses on the former regulatory theory as this has a direct impact on the development or generation and adoption of innovative healthcare products and services, relating to the external collaboration between healthcare service providers and healthcare insurers.

In the healthcare sector, regulatory bodies play a pivotal role in balancing cooperation and competition by means of reforms introduced through legislation (Baretta, 2008; Mur-Veeman, Eijkelberg \& Spreeuwenberg, 2001; Provan, 1984). According to Baretta (2008), within the healthcare sector, regulatory bodies can influence the level of competition by, for example:

- Increasing the number of healthcare service providers authorised to provide healthcare services,

- Choosing a competitive financing model for healthcare service providers,

- Establishing the same spheres of activity for many (or all) healthcare service providers, and

- Adopting mechanisms for evaluating performance of healthcare service providers based on the pursuit of individual goals.

Therefore, a regulatory body in the healthcare sector is potentially able to act as a coordinator system through its own power to balance competition and cooperation (Baretta, 2008).

\section{5}

\section{Model and hypotheses development}

Based on the abovementioned theoretical underpinnings, a conceptual factor model $a$ priori was developed, which allowed for deductive reasoning to hypothesise the structure beforehand and to then evaluate its goodness of fit to data (Kline, 2011). The researchers formulated explicit hypotheses regarding the number of latent variables and how they relate to the observed variables.

$\mathrm{H}$ 1: A positive correlation exists between the (a) level of new product innovation by health insurers and (b) entrepreneurial orientation.

$\mathrm{H}$ 2: A positive correlation exists between the (a) level of new product innovation by health insurers and (b) external collaboration between (c) health insurers and (d) healthcare service providers.

$\mathrm{H}$ 3: The relation between the (a) level of new product innovation by health insurers and (b) entrepreneurial orientation is moderated by perceived strategic regulatory factors necessary for encouraging health insurer product innovation, such that the relation is weaker where these strategic regulatory factors have lower presence and stronger where they have higher presence.

$\mathrm{H}$ 4: The relation between the (a) level of new product innovation by health insurers and (b) external collaboration between (c) health insurers and (d) healthcare service providers is moderated by perceived strategic regulatory factors necessary for encouraging health insurer product innovation, such that this relation is weaker where these strategic regulatory factors have lower presence and stronger where they have higher presence.

Figure 1 highlights the hypothesised relationships between the independent variables (EO, external collaboration and regulation) and the dependent variable (health insurer product innovation). Each construct is operationalised in the following section. 


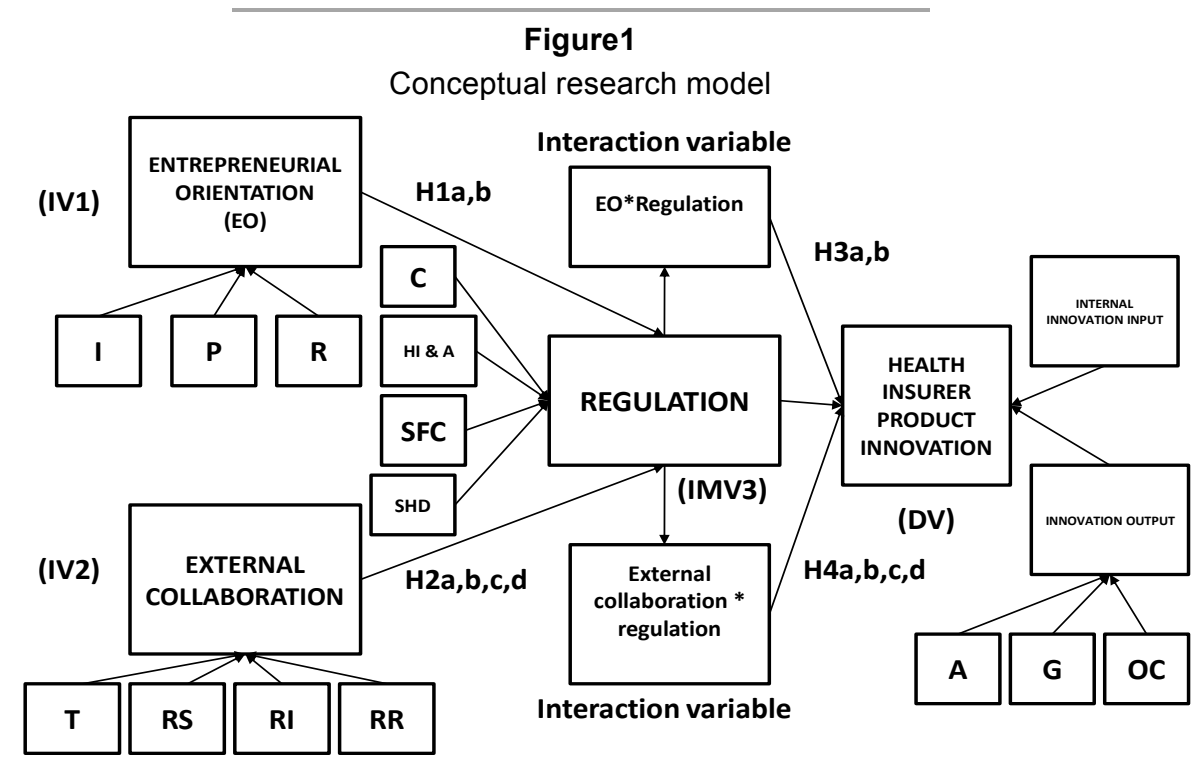

6

\section{Research design}

The research study was based on explanatory research and followed a quantitative approach. The methodological approach adopted, was an online survey that was administered by an independent business research organisation in order to ensure data confidentiality of participants. The questionnaire was delivered via the internet in the form of an online questionnaire and elicited perceptions of respondents at senior managerial levels. Management perceptions are the preferred measure of CE (Antoncic \& Hisrich, 2004).

\subsection{Population}

The sampling frame of participants in the supply and demand side structures of the healthcare value chain, was determined by consulting the Council for Medical Schemes (2011) Annual 2010/11 Report. This report provided the sampling frame for health insurers and health insurer administrators and identified the sampling frame for healthcare service provider disciplines responsible for the majority of annual healthcare benefits paid in the industry. The focus of the sample populations were CEOs and senior executives of health insurers, health insurer administrators and healthcare service providers, representing demand and supply side structures as indicated in the private healthcare value chain (Stremersch, 2008). A personalised e-mail was sent from the researcher, positioning the study and stating the objectives and the value of the research to the South African private healthcare industry. The e-mails were followed up with periodic telephone calls.

In total, 154 respondents completed the online survey, however 15 respondents did not fully complete the survey and their responses were not included in the data set, leaving the total number of respondents at 139 . The health insurer response rate achieved was 24 per cent, totalling 34 responses. Of these 14 were open health insurers (51.8 per cent of all registered open health insurers) and 20 closed health insurers (27.3 per cent of all registered closed health insurers). Following the definitions of the Council for Medical Schemes' annual report, 50 per cent of large open health insurers ( $>30,000$ beneficiaries) and 60 per cent of the number of large closed health insurers (>30,000 beneficiaries) responded (Council for Medical Schemes, 2011). The percentage of private healthcare lives covered by the 34 health insurers that responded, totalled 68 per cent of all private healthcare lives in the South African private healthcare industry.

The health insurer administrator responses totalled 83. The responses from the general practitioner representative organisations totalled 11. Seven responses were received from the 
specialist representative organisations and four of the five private hospital groups responded.

Based on the sampling method and response rates, the researcher considers all samples as adequate representations of their respective populations.

\subsection{Structure of the research instrument}

The questionnaire consisted of parts $\mathrm{A}$ to $\mathrm{E}$ (detailed below) and all were measured using a 7-point Likert scale.

Section A - This section focused on biographical data (control variables for the study, i.e. firm size, firm age, industry sector, geographical area). This section also included questions derived from the literature on organisational competitive capability described by Ireland et al. (2009).

Section B - This section focused on entrepreneurial orientation as one of the independent variables. The EO instrument was based on the original Covin and Slevin (1989) scale as modified by Kreiser, Marino and Weaver (2002). The EO dimensions measured in this section were innovativeness, proactiveness and risk taking.

Section C - This section focused on external collaboration between health insurers and health care service providers and provided the data to measure this independent variable. Zillich's et al. (2005) instrument used to measure physician-pharmacist collaboration (PPCI) from a physician perspective, formed the basis for the collaboration measurement instrument. This instrument was adapted to measure health insurer, health insurer administrator and healthcare service provider collaboration from the respective perspectives. As per Porter and Teisberg (2006), this instrument was designed to measure the extent to which the healthcare insurer and healthcare service provider relationships needs to be restructured in order to facilitate value-based competition or innovation in healthcare.

Specific constructs of trustworthiness (T), role specification (RS), relationship initiation (RI) and health insurer and healthcare service provider relationship restructure (RR) were also measured in this section.

Section D -Thefocus here was on regulation as the independent moderator variable of the researcher's model, affecting product innovation by health insurers. The section was not based on a previous instrument and the construction of the instrument followed guidelines in terms of strategic regulatory factors present in healthcare regulation, encouraging health insurer product innovation and value-based health care delivery by Porter and Teisberg (2006), and Christensen, Grossmann and Hwang (2009). The instrument was designed to measure the following constructs:

- Encourage competition in healthcare to reduce prices,

- Improve health insurance and access to private healthcare,

- Standards for coverage,

- Structure of health care delivery.

Section E - Here the focus was on measuring the dependent variable, health insurer product innovation. The questionnaire was designed to measure two aspects of this construct, internal innovation input and innovation output. Internal innovation input was measured by questioning the research and development intensity of organisations, and innovation output was measured through items on the following constructs: innovation adoption, innovation generation and organisational competitiveness. This section of the questionnaire was based on combining and adapting previous measurement instruments used by Pérez-Luño et al. (2011), Rosenbusch et al. (2011) and the GEM Global report of 2010 for internal innovation input and innovation output (Kelly, Bosma \& Amoros, 2010).

\subsection{Common method bias}

According to Podsakoff, Mackenzie, Lee and Podsakoff (2003), common method biases arise from having a common rater, measurement context and item context, or from characteristics of the items themselves, and in any given study, it is possible for several of these factors to be present. It is therefore important to evaluate the conditions under which the data are obtained to assess the extent to which method biases may be a problem (Podsakoff et al., 2003). Podsakoff et al. (2003) indicate that method biases are likely to be particularly powerful in studies in which the 
data for both the predictor and criterion variable are obtained from the same person in the same measurement context using the same item context and similar item characteristics.

The researcher applied procedural controls through obtaining measures of the criterion variable from other sources. By introducing an independent scale of organisational competitive capability (Ireland et al., 2009)he could check and correlate the criterion variable. Furthermore, the respondents clustered around measures of innovation input were compared in terms of the dependent variable measures of innovation adoption and generation and organisational competitiveness, as a validity check of the dependent variable measures. The researcher made sure to respect respondent anonymity.

The researcher also applied confirmatory factor analysis (CFA) to the empirical data of the scales of each construct to check whether a single factor could account for most of the variance in the data as would occur if there was strong method bias in the responses (Podsakoff et al., 2003). The CFA method is a more recent and more sophisticated test of common method bias than ones like the Harman single-factor test that uses exploratory factor analysis (EFA) to examine the unrotated factor solution for the dimensionality in the data (Podsakoff et al., 2003). The basic assumption of these tests is that if a substantial amount of common method variance is present, either a single factor will emerge from the factor analysis or one general factor will account for the majority of the covariance among the measures (Podsakoff et al., 2003).

\subsection{Structural equation modelling (SEM)}

The researcher's model (Figure 1) comprised the relationships among the constructs ofEO, external collaboration, regulation and health insurer product innovation. It also specified their respective measurement scales, which tests for support by the empirical data gathered. Kline (2011) explains that models may be tested in three contexts, first a strictly confirmatory context in which the researcher's model is accepted or rejected based on the fit of the data. Second a less restrictive context of multiple alternative models in which some of the models may be retained and others rejected, and third, a context of model generation in which the researcher's model is modified if the empirical data does not fit (Kline, 2011). The research study is best characterised in the context of model generation as EFA was applied to determine the dimensionality of the constructs of the model and then CFA was applied to test and compare both the empirically and theoretically derived factor structures. Although SEM was proposed to evaluate the model, the sample size realised did not allow the application of this statistical procedure. Instead, regression analysis was applied to each of the research hypotheses separately to test the structure of the model and ignoring the psychometric properties of scale reliability and validity.

\subsection{EFA and CFA}

The measurement adequacy of the scales of each of the model's constructs was evaluated separately using first reliability measures, then EFA and then CFA, of empirically and theoretically based models.

The researcher studied the construct validity of the scales using the statistical techniques of CFA and EFA. EFA was used to identify the number of constructs and the underlying factor structure (Suhr, 2006). It was used to explore the possible underlying factor structure of a set of measured variables without imposing any preconceived structure on the outcome (Child, 1990).

In the present research, CFA was used as a statistical tool for testing hypotheses about convergent and discriminant validity (Kline, 2011). CFA allows the researcher to test that a relationship between the observed variables and their underlying latent construct(s) exists. Analysis of the results of EFA was also considered in evaluating construct validity, particularly when the CFA results were weak.

As the sample size achieved in the research did not allow for factor analysis of all 74 items of the research instrument simultaneously, CFA and EFA were performed in turn on all the items of the scales and subscales designed to measure each of the constructs of the model. Thus, separate factor analyses were computed on the items of the subscales of the independent variables of the model (EO, 
external collaboration and regulation), on the items of the subscales of the dependent variable, health insurer product innovation (health insurer product innovation adoption, health insurer product innovation generation and organisational competitiveness). Thereafter, a higher order CFA was used on the subscale scores (rather than the item scores) to test the model for a second-order factor structure (Hair, Black, Babin \& Anderson, 2010). This second order CFA was performed on the subscale scores of EO, external collaboration, regulation and health insurer product innovation to establish construct validity at the subscale level. This second order CFA aimed to assess whether the subscales that purported to reflect the same construct were more highly intercorrelated than subscales purported to reflect different constructs. Multiple linear regression was then performed to test the structural aspects of the model. The regression equation of the model (refer Figure 1) was:

Level of Health Insurer Product innovation $=$ $\mathfrak{a}+\beta_{1}(\mathrm{EO})+\beta_{2}($ External

Collaboration(T,RS,RI) $)+\beta_{3}($ External

Collaboration $(\mathrm{RR}))+\beta_{4}($ Regulation $)+$

$\beta_{5}($ EO $*$ Regulation $)+\beta_{6}$ (External

Collaboration (T,RS,RI)*Regulation) +

$\beta_{r}($ External Collaboration(RR)*Regulation)

\subsubsection{Independent variable 1}

Entrepreneurial orientation (EO) - measurement constructs: innovativeness (I), proactiveness $(\mathrm{P})$, and risk-taking $(\mathrm{R})$. The EO instrument was based on the original Covin and Slevin (1989) scale, as modified by Kreiser, Marino and Weaver (2002).

\subsubsection{Independent variable 2}

External collaboration - measurement constructs: trustworthiness $(\mathrm{T})$, role specification (RS), relationship initiation (RI) and relationship restructure (RR). The external collaboration measurement instrument was based on the instrument used by Zillich, Douchette, Carter and Kreiter (2005). The instrument was further adapted to include items designed to measure the extent to which the health insurer and healthcare service provider relationship needs to be restructured as indicated by Porter and Teisberg (2006).

\subsubsection{Independent variable 3}

Regulation - measurement constructs: increased competition (C), increased health insurance and access (HI \& A), standards for coverage (SFC) and, structure of health care delivery (SHD). This section is not based on a previous instrument and the construction of the measurement instrument followed guidelines in terms of strategic regulatory factors encouraging healthcare innovation by Porter and Teisberg (2006) and Christensen, Grossman and Hwang (2009).

\subsubsection{Dependent variable}

Health insurer product innovation measurement constructs: Internal innovation input and innovation output. This section included measurement constructs for innovation output, which contextualised both innovation adoption (A) and generation (G), as well as organisational competiveness (OC). This section was adapted from previous measurement instruments used by Perez-Luno, Wiklund and Cabrera (2011) and Rosenbusch, Brinkman and Bausch (2011).

\section{7}

\section{Results and discussion}

The majority of respondents (60 per cent) represent health insurance administrators (HIAs), 25 per cent of respondents represent health insurers (HIs), and almost 16 per cent represent healthcare service providers. Of the 34 health insurers who responded, 20 (59 per cent) represented closed health insurers and 14 (41 per cent) represented open health insurers. The majority (88 per cent) of respondents worked in organisations that operated nationally. Of the other respondents, half worked in organisations that operated primarily in Gauteng and the others operated primarily in KZN, Limpopo, Western Cape, North West and Eastern Cape. Other characteristics of the organisations represented by the respondents are firm age and firm size in terms of number of permanent employees and membership/patient base.

These results show that:

- Nearly three-quarters of healthcare service providers (73 per cent) had been in 
operation for more than 20 years and almost two-thirds had a staff complement of 10 or fewer. Their membership/patient base ranged between under 5000 to over 100000.

- Over half of health insurer administrator organisations (59 per cent) had been in operation for between 11 and 20 years. Almost all the organisations (98 per cent) employed more than 200 staff. Furthermore almost all (83 per cent) had a membership/patient base of more than 100 000 for the current financial year.

- A third of the health insurers had been in operation for between 11 and 20 years and 56 per cent for longer. Almost half (47 per cent) employed 10 or fewer staff members, while 26 per cent employed more than 200 staff. Almost half (47 per cent) had a membership/patient base for the current financial year of over 100000 .

The validity of the theoretically derived scales of the model was investigated using EFA to see whether there was evidence of empirically derived combination of items that differed from theoretical expectation. If so, the empirically derived scales were retained and CFA was applied to both the original theoretical as well as the new empirical scales and tested for model fit for each construct. The criterionrelated validity of the scales of the dependent variable was also considered. Three sets of factor analyses (EFA and CFA) were performed in turn on all the items of the scales and subscales designed to measure each of the constructs of the model (EO, external collaboration and regulation). A fourth set of factor analyses was performed on the items of the subscales of the dependent variable, health insurer product innovation (health insurer product innovation adoption, health insurer product innovation generation and organisational competitiveness). Thereafter, a higher order CFA was used on the subscale scores (rather than the item scores) to test the model for a second-order factor structure in order to establish construct validity at the subscale level.

\subsection{EO}

The Cronbach alpha values of the theoretically derived measures of the constructs of regulation, entrepreneurial orientation (EO) and external collaboration variables are all adequate and above the 0.7 cut-off level for internal consistency as indicated by Hair et al. (2010).

\subsubsection{EFA Results}

The data matrix of the nine EO variables showed sufficient correlations to proceed with the application of factor analysis as the KaiserMeyer-Olkin (KMO) measure of sampling adequacy was high at 0.9 and Bartlett's test of sphericity was significant $(\mathrm{p}<0.001)$

\subsubsection{CFA Results}

The CFA results, using the theoretically derived scales for EO indicate that there is a strong relationship between EO as an observed variable and its underlying latent constructs. The factor loadings for all three latent variables are in the range of \pm 0.8 to \pm 0.93 . This is high and practically significant and is an indication that the factors account for more than 70 per cent of the variance of the variables.

There is supportive evidence of the construct validity of EO.

\subsection{External collaboration}

\subsubsection{EFA results}

The data matrix of the 18 External Collaboration variables showed sufficient correlations to proceed with the application of factor analysis as the sampling adequacy KMO measure was high at 0.8 and Bartlett's test of sphericity was significant $(\mathrm{p}<0.001)$.

The EFA results show that two items: 'quality patient care mutual dependency', and 'product innovation mutual dependency' load highly on a different factor from the other items purported to measure role specification (RS). These items were moved accordingly, and the resultant scale was termed the empirically derived scale.

\subsubsection{CFA results}

CFA was applied to both the theoretically and empirically derived scales of external collaboration, and their parameter values and model fits were compared in order to decide on the measurement scales that would ultimately be used in the regression analyses to test the model of the research. 
The CFA results using the empirically derived scales for external collaboration indicated that there is a moderate to strong relationship between external collaboration as an observed variable and its underlying latent constructs, trustworthiness $(\mathrm{T})$, role specification (RS), relationship initiation (RI) and relationship restructure (RR). Using the empirically derived scales for the CFA estimates, the factor loadings for trustworthiness are in the range of \pm 0.65 to \pm 0.86 , which are considered to be practically significant. The factor loadings for role specification are in the range of \pm 0.56 to 0.88 , which likewise are considered to be practically significant. The factor loadings for relationship initiation are also considered to be practically significant and are in the range of \pm 0.56 to \pm 0.86 , and the factor loadings for relationship restructure are in the range of \pm 0.7 to \pm 0.85 , indicating practical significance.

Using both the theoretically and the empirically derived scales, the CFA has confirmed that two items, which were expected to measure the latent variable 'role specification' (RS), fit better measuring the latent variable, 'relationship initiation' (RI). In both cases, the factor loadings using the empirically derived scales have slightly reduced when these items were moved to the latent variable, relationship initiation. The construct validity of the empirically derived external collaboration variable was therefore supported.

\subsection{Regulation (moderator variable)}

According to the researcher's model, regulation was expected to serve as a moderating variable, whereby the relationship between EO and health insurer product innovation, and between external collaboration and health insurer product innovation, were expected to be weaker when the presence of strategic regulatory factors are low and stronger when they are high. Furthermore, according to theory, the regulation construct was expected to reflect four underlying regulation factors (increased competition, health insurance and access, standards for coverage, and structure of healthcare delivery).

\subsubsection{EFA results}

The data matrix of the 16 regulation variables showed sufficient correlations to proceed with the application of factor analysis as the sampling adequacy measure of The KMO measure of sampling adequacy was high at 0.9 and Bartlett's test of sphericity was significant $(\mathrm{p}<0.001)$.

\subsubsection{CFA results}

The CFA results using the theoretically derived scales for regulation indicated a moderately strong to strong relationship between regulation as an observed variable and its underlying latent constructs; increased competition; health insurance and access; standards for coverage and structure of healthcare delivery.

The factor loadings for the increased competition variable are considered to be practically significant and are in the range of \pm 0.56 to \pm 0.88 . The factor loadings for health insurance and access are in the range of \pm 0.67 to \pm 0.85 , indicating practical significance. The factor loadings for standards for coverage are in the range of \pm 0.42 to \pm 0.93 indicating practical significance for all items except item 13. Item 13, however, still meets the minimum level for interpretation of structure. The factor loadings for structure of healthcare delivery are in the range of \pm 0.8 to \pm 0.93 , indicating practical significance.

\subsection{Product innovation (dependent variable)}

The Cronbach alpha values for the theoretically derived measures of the innovation generation construct and the organisational competitiveness construct (the dependent variable, health insurer product innovation), are around 0.9 , indicative of high internal consistency reliability. However, the Cronbach alpha and average inter-item correlations values for innovation adoption, designed to measure a dimension of health insurer product innovation, are at 0.5 and 0.28 respectively, indicating the presence of unacceptably high error variance in the scores of this scale.

\subsubsection{EFA results}

The data matrix of the 13 health insurer product innovation variables showed sufficient correlations to proceed with the application of factor analysis, as the sampling adequacy measure of theKMO measure of sampling 
adequacy was high at 0.9 and Bartlett's test of sphericity was significant $(\mathrm{p}<0.001)$.

The EFA results show that one of the items expected to measure innovation adoption; 'generated new HI for organisation' and one of the items expected to measure innovation generation; 'generated new HI making your organisation competitive' loaded highly on different factors.

\subsubsection{CFA results}

CFA was applied to both the theoretically and empirically derived scales of health insurer product innovation (innovation output). Their respective parameter values and model fits were compared in order to decide on the composition of the measurement scales of the dependent variable to be used in the regression analyses designed to test the researcher's model.

The CFA results using the empirically derived scales for health insurer product innovation indicated that there is a moderate to strong relationship between health insurer product innovation as an observed variable and two of its underlying latent variables, innovation generation and organisational competitiveness. The relationship between health insurer product innovation output and its latent variable innovation adoption is weaker. The factor loadings for innovation generation are in the range of \pm 0.67 to \pm 0.85 , indicating practical significance. The factor loadings for organisational competitiveness are in the range of \pm 0.8 to \pm 0.96 , indicating practical significance.

\subsection{Second order confirmatory factor analysis}

Second order CFA was performed at the subscale level (rather than at the item level as used in the other CFAs) to confirm whether the subscales of the four constructs of the model did indeed reflect these constructs as expected from the theory. Table 1 presents the model estimates for the second order analysis, highlighting the second order constructs (red colour indicator).

Table 1

Model estimates second order CFA

\begin{tabular}{|l|l|l|c|c|}
\hline Variables & $\begin{array}{c}\text { Parameter } \\
\text { estimate }\end{array}$ & $\begin{array}{c}\text { Standard } \\
\text { error }\end{array}$ & $\begin{array}{c}\text { T } \\
\text { statistic }\end{array}$ & $\begin{array}{c}\text { Prob. } \\
\text { level }\end{array}$ \\
\hline (EO)-1->[INNOVATI] & 0.934 & 0.018 & 53.2 & 0.000 \\
\hline (EO)-2->[PROACTIV] & 0.913 & 0.02 & 46.4 & 0.000 \\
\hline (EO)-3->[RISK TAK] & 0.839 & 0.029 & 29.1 & 0.000 \\
\hline (External Collaborati)-4->[TRUSTWOR] & 0.703 & 0.061 & 11.5 & 0.000 \\
\hline (External Collaborati)-5->[ROLE SPE] & 0.722 & 0.06 & 12.1 & 0.000 \\
\hline (External Collaborati)-6->[RELATIONSHIP] & 0.653 & 0.065 & 10.1 & 0.000 \\
\hline (External Collaborati)-7->[RESTRUCT] & 0.325 & 0.088 & 3.69 & 0.000 \\
\hline (Regulation)-8->[ENCOURAG] & 0.701 & 0.05 & 14 & 0.000 \\
\hline (Regulation)-9->[HIA IMPR] & 0.858 & 0.033 & 26.3 & 0.000 \\
\hline (Regulation)-10->[IMPROVE ] & 0.789 & 0.04 & 19.7 & 0.000 \\
\hline (Regulation)-11->[HD STRUC] & 0.816 & 0.037 & 22.1 & 0.000 \\
\hline (HI Product Innovatio)-12->[Adoption] & 0.179 & 0.087 & 2.06 & 0.040 \\
\hline (HI Product Innovatio)-13->[Generati] & 0.880 & 0.03 & 29.8 & 0.000 \\
\hline (HI Product Innovatio)-14->[Organisa] & 0.890 & 0.029 & 30.9 & 0.000 \\
\hline
\end{tabular}

Consistent with the CFA results conducted at item level, the CFA analysis failed to confirm the validity of the relationship restructure (RR) subscale expected to reflect external collaboration, and the innovation adoption subscale designed to reflect health insurer product innovation.

These results lend further evidence to the revision of the theoretically derived scales and subscales of the model to strengthen the psychometric quality of the predictor variables of the research model.

\subsubsection{Summary of CFA analyses}

Table 2 presents the model fit results. Model fit is also presented using theoretically and empirically derived scales for the external 
collaboration variable (independent variable) and the health insurer product innovation variable (dependent variable). Second order results have also been used as a method to improve model fit.

Table 2

Model fit results

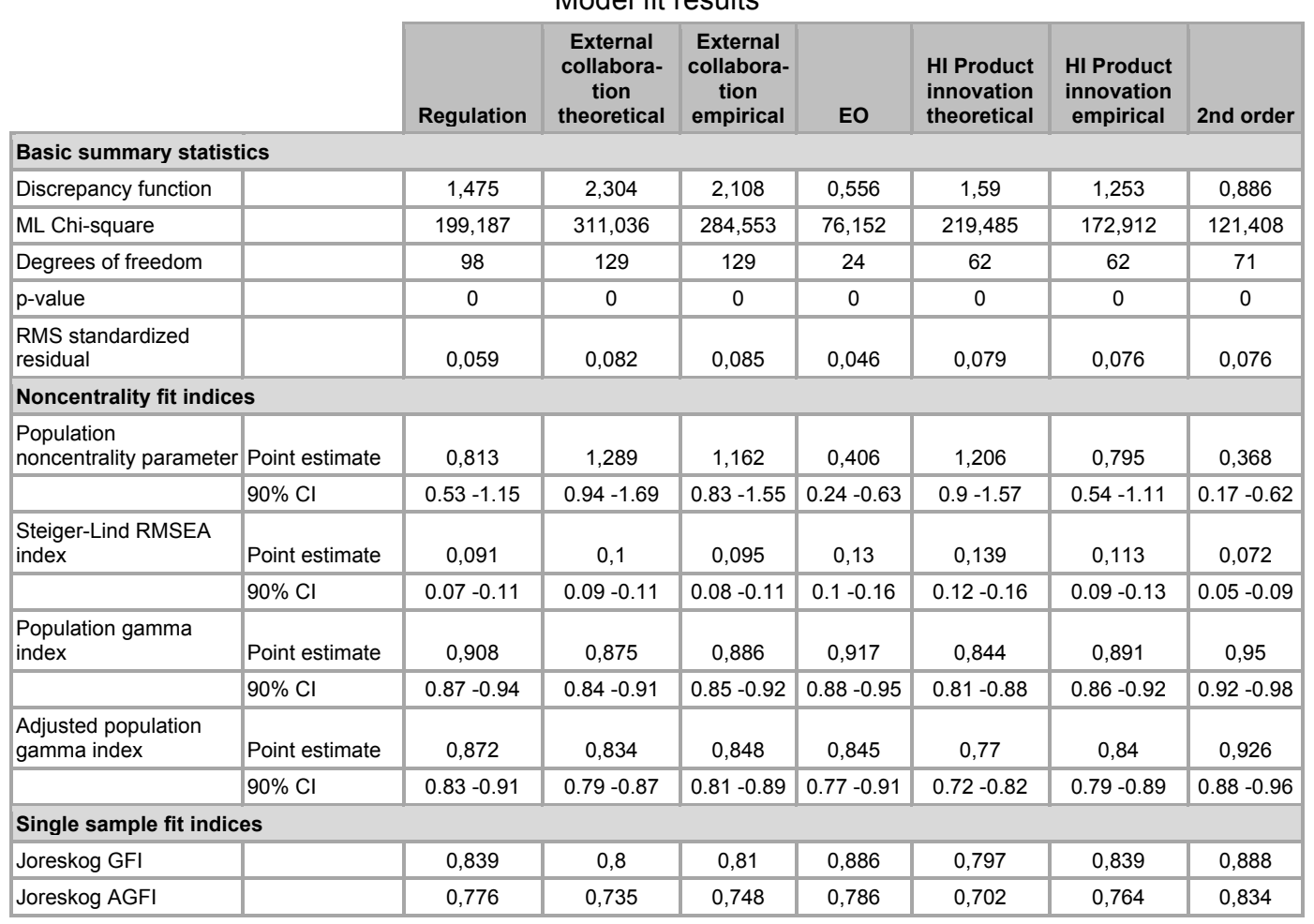

In Summary:

- The chi-square statistic values for all the variables and the second order analysis are relatively large and the corresponding $\mathrm{p}$ values are small. This is an indication that the proposed theory does not fit reality well.

- The Steiger-Lind RMSEA index values for all the variables and second order are all greater than 0.05 , indicating weak model fit.

- The population gamma index values for all the variables and second order are all smaller than 0.95 , indicating weak model fit.

- The adjusted population gamma index values for all the variables and second order are all smaller than 0.95 , indicating weak model fit.

- The Joreskog GFI index values for all the variables and second order are all smaller than 0.9 or 0.95 , indicating weak model fit.

- The Joreskog AGFI index values for all the variables and second order are all smaller than 0.95 , indicating weak model fit.

Assessing the standardised root mean residual (SRMR) values for all the variables and second order, indicated values smaller than 0.1 (values are within the guideline), indicating better model fit. The larger discrepancy function values for all the variables and second order indicate that the model does not fit the data well. The model fit analysis shows weak model fit, despite attempting to improve the values using the empirically derived instead of the theoretically derived scales.

The reliabilities presented for the theoreticcally based scales have been revised to include the reliabilities of the empirically based ones. In Table 3 the reliabilities of the empirically based scales are marked with an asterisk. 
Table 3

Reliabilities of the empirically based scales

\begin{tabular}{|c|c|c|c|}
\hline & $\begin{array}{c}\text { Number of } \\
\text { items }\end{array}$ & Cronbach alpha & $\begin{array}{c}\text { Average inter-item } \\
\text { correlation }\end{array}$ \\
\hline \multicolumn{4}{|l|}{ Regulation } \\
\hline Increased competition & 3 & 0.786 & 0.56 \\
\hline $\mathrm{HI} \&$ access to private healthcare & 6 & 0.899 & 0.61 \\
\hline Standards for coverage & 4 & 0.779 & 0.48 \\
\hline Structure of healthcare delivery & 3 & 0.913 & 0.79 \\
\hline \multicolumn{4}{|l|}{ EO } \\
\hline Innovativeness & 3 & 0.871 & 0.70 \\
\hline Proactiveness & 3 & 0.892 & 0.74 \\
\hline Risk taking & 3 & 0.919 & 0.80 \\
\hline \multicolumn{4}{|l|}{ External collaboration } \\
\hline Trustworthiness $(\mathrm{T})$ & 6 & 0.881 & 0.57 \\
\hline Role specification (RS) & 5 & 0.695 & 0.33 \\
\hline Relationship initiation (RI) & 2 & 0.871 & 0.77 \\
\hline Relationship restructure (RR) & 5 & 0.896 & 0.64 \\
\hline External collaboration & 18 & 0.879 & 0.28 \\
\hline External collaboration $(T, R S, R I)^{*}$ & 13 & 0.872 & 0.37 \\
\hline \multicolumn{4}{|l|}{ Health insurer product innovation } \\
\hline Innovation adoption & 3 & 0.509 & 0.28 \\
\hline Innovation adoption* & 2 & 0.627 & 0.46 \\
\hline Innovation generation & 7 & 0.907 & 0.59 \\
\hline Innovation generation* & 6 & 0.905 & 0.62 \\
\hline Organisational competitiveness & 3 & 0.921 & 0.81 \\
\hline Organisational competitiveness* & 4 & 0.929 & 0.78 \\
\hline
\end{tabular}

*empirically derived scales

- The reliability of 'innovation adoption', although improved using the empirically derived rather than the theoretical scale, is still unacceptably low - the Cronbach alpha value has increased from 0.51 to 0.63 and the average inter-item correlation has increased. Thus the construct of innovation adoption was excluded from the model due to its poor reliability and validity results.

- The Cronbach alpha value using the empirical result for 'innovation generation' shows little change and the Cronbach alpha value for the new organisational competitiveness scale is similar.

- The empirically derived 'external collaboration' scale (comprising trustworthiness $(\mathrm{T})$, role specification (RS) and relationship initiation (RI) items) reliability is good, with improved average inter-item correlation, using the empirically derived instead of the theoretically derived scale. The average inter-item correlation for innovation generation using the empirically derived scale has improved slightly, although the inter-item correlation for organisational competitiveness has decreased slightly, using this scale.

\section{8}

\section{Conclusions and recommendations}

Theoretical development is enriched in a number of ways by this study. The importance of EO in organisational performance has been recognised in the literature and this study revealed that EO is critical to health insurer product innovation in the private healthcare industry in South Africa, and provides additional grounding for statements about the strong positive effect of EO on organisational performance (Green, Covin \& Slevin, 2008; Morris \& Sexton, 1996; Wiklund \& Shepherd, 2005; Zahra \& Covin, 1995).

The practical implications stemming from this study, for healthcare executives are: 
- To ensure that their organisations have the necessary internal innovation input capacity to drive innovation output, and

- To ensure that external collaboration between health insurers and healthcare service providers are more actively focused on by actors in the healthcare value chain. Both the supply and demand side structures (subgroups identified for the purposes of this study) have indicated recognition for the fact that the restructuring of relationships between health insurers and healthcare service providers is a necessary driver for collaboration in terms of health insurer product innovation progress and success. As supported by Porter and Teisberg (2006), this finding suggests that executives of health insurers should actively focus on the following initiatives as examples that could drive greater innovation activities between health insurers and healthcare service providers, such as to:

- Assist healthcare service providers to maintain more up-to-date patient information,

- Reward healthcare service providers for improving results over time,

- Introduce simplified billing practices in terms of contractual arrangements between health insurers and healthcare service providers,

- Reduce administrative complexities by eliminating paperwork and transactions,

- Make new investments in technology and related infrastructure to facilitate collaboration practices.

The policy implications highlighted by this study relate to the perception of the low levels of strategic regulatory factors present in healthcare regulation in South Africa, necessary to drive health insurer product innovation. The strategic regulatory factors necessary to drive health insurer product innovation are increased health insurance and access to health insurance, standards for coverage, and the structure of healthcare delivery (Porter \& Teisberg, 2006). Healthcare delivery is viewed as a critical component in terms of driving value-based competition and innovation in healthcare (Porter \& Teisberg, 2006). Healthcare executives need to work with, and actively lobby regulators to investigate these aspects, which could ignite both demand and supply side innovation activities in the healthcare value chain of the private healthcare industry of South Africa.

\subsection{Limitations of the study}

The research study has several limitations that could provide opportunities for future research. The following limitations have been identified:

- The research study only focused on health insurers, health insurer administrators and healthcare providers and did not take into account any significant contribution to product innovation from other actors in the healthcare value chain like employers, corporate and individual pharmacies and pharmaceutical manufacturers.

- The measurement scales for innovation adoption need to be refined due to low reliability and validity.

\subsection{Recommendations for future research}

Future research could involve a larger sample of actors in the demand and supply side structures of the South African private healthcare value chain, focusing especially on supply side innovation and the structure of healthcare delivery. According to Mintzberg (2011) healthcare actors need to build systems that both promote health and treat illness and to do that, more cooperation not more competition between healthcare actors is required. Future research could focus on the relationship between market dynamism in the private healthcare industry in South Africa and external collaboration between the various actors in the private healthcare value chain.

Based on the results of this study, further investigation of the impact of regulation on innovation progress in the private healthcare industry is required due to the importance of regulation balancing cooperation and competition in the healthcare value chain. The perceived strategic regulatory factors necessary for encouraging health insurer product innovation should be further explored in terms of how this could influence innovation activities in the private healthcare industry of South Africa. 


\section{References}

ALOULOU, W. \& FAYOLLE, A. 2005. A conceptual approach of entrepreneurial orientation within small business context. Journal of Enterprising Culture, 13:21-45.

ANTONCIC, B. \& HISRICH, R.D. 2001. Intrapreneurship: Construct refinement and cross cultural validation. Journal of Business Venturing, 16:495-527.

ANTONCIC, B. \& HISRICH, R.D. 2004. Corporate entrepreneurship contingencies and organizational wealth creation. Journal of Management Development, 2:518-550.

BARETTA, A. 2008. The functioning of co-opetition in the healthcare sector: An explorative analysis. Scandinavian Journal of Management, 24:209-220.

BARNEY, J. 1991. Firm resources and sustained competitive advantage. Journal of Management, 17:99-120. CENTRE FOR DEVELOPMENT AND ENTERPRISE. 2011. Reforming healthcare in South Africa. Johannesburg: Centre for Development and Enterprise, Research report no. 18.

CHILD, D. 1990. The essentials of factor analysis, Cassel Educational Limited: London.

CHRISTENSEN, C.M., GROSSMAN, J.H. \& HWANG, J. 2009. The innovator's prescription: A disruptive solution for health care, McGraw-Hill: New York.

COUNCIL FOR MEDICAL SCHEMES. 2011. Annual report for 2010/2011. Pretoria: Council for Medical Schemes.

COVIN, J.G., IRELAND, R.D. \& KURATKO, D.F. 2003. The exploration and exploitation functions of corporate venturing. Paper presented at the Academy of Management meetings. Seattle, WA.

COVIN, J.G. \& SLEVIN, D.P. 1989. Strategic planning of small firms in hostile and benign environments. Strategic Management Journal, 10:75-87.

DAMANPOUR, F. \& WISCHNEVSKY, J.D. 2006. Research on innovation in organisations: distinguishing innovation-generating from innovation-adopting organisations. Journal of Engineering and Technology Management, 23:269-291.

DASSLER, T. 2006. Combining theories of regulation - Proposing a framework for analysing regulatory systems worldwide. Utilities Policy, 14:31-43.

DESS, G.G., IRELAND, R.D., ZAHRA, S.A., FLOYD, S.W., JANNEY, J.J. \& LANE, .PJ. 2003. Emerging issues in corporate entrepreneurship. Journal of Management, 29:351-378.

DESS, G.G. \& LUMPKIN, G.T. 2005. The role of entrepreneurial orientation in stimulating effective corporate entrepreneurship. Academy of Management Executive, 19:147-156.

DESS, G.G., LUMPKIN, G.T. \& COVIN, J.G. 1997. Entrepreneurial strategy making and firm performance. Strategic Management Journal, 18:677-695.

DRUCKER, P. 1979. The practice of management. Pan Books: London.

GOEDHUYS, M. \& VEUGELERS, R. 2011. Innovation strategies, process and product innovations and growth: Firm-level evidence from Brazil. Structural Change and Economic Dynamics, Article in Press. GREEN, K.M., COVIN, J.G. \& SLEVIN, D.P. 2008. Exploring the relationship between strategic reactiveness and entrepreneurial orientation: The role of structure-style fit. Journal of Business Venturing, 23:356-383.

GUTH, W.D. \& GINSBERG, A. 1990. Corporate entrepreneurship. Strategic Management Journal, 11:5-15. HAIR, J.F., BLACK, W.C., BABIN, B.J. \& ANDERSON, R.E. 2010. Multivariate data analysis: A global perspective, New Jersey: Pearson Education Inc.

HUNT, S.D. \& ARNETT, D.B. 2006. Does marketing success lead to market success? Journal of Business Research, 59:820-828.

HUNT, S.D. \& MORGAN, R.M. 1996. The resource-advantage theory of competition: Dynamics, path dependencies, and evolutionary dimensions. Journal of Marketing, 60:107-114.

IRELAND, R.D., COVIN, J.G. \& KURATKO, D.F. 2009. Conceptualising corporate entrepreneurship strategy. Entrepreneurship Theory and Practice, I 33:19-46.

KELLY, D.J., BOSMA, N. \& AMOROS, J.E. 2010. Global Entrepreneurship Monitor: 2010 Global Report. Babson College, Universidad del Desarrollo, London Business School.

KLINE, R. 2011. Principles and Practice of Structural Equation Modelling, New York: The Guilford Press. 
KNIGHT, G.A. 1997. Cross-cultural reliability and validity of a scale to measure firm entrepreneurial orientation. Journal of Business Venturing, 12:213-225.

KOUZES, J.M. \& POSNER, B.Z. 2007. The leadership challenge, San Francisco: John Wiley \& Sons Inc. KREISER, P.M., MARINO, L.D. \& WEAVER, K.M. 2002. Assessing the psychometric properties of the entrepreneurial orientation scale: A multi country analysis. Entrepreneurship Theory and Practice: 71-94. LI, Y., LIU, Y. \& ZHAO, Y. 2006. The role of market and entrepreneurship orientation and internal control in the new product development activities of Chinese firms. Industrial Marketing Management, 35:336-347. LI, Y., HUANG, J. \& TSAI, M. 2009. Entrepreneurial orientation and firm performance: The role of knowledge creation process. Industrial Marketing Management, 38:440-449.

LUMPKIN, G.T. \& DESS, G.G. 1996. Clarifying the entrepreneurial construct and linking it to performance. Academy of Management Review, 21:135-166.

MAJONE, G. 2010. Regulating Europe, Routledge: London: New York.

MCLEOD, H. \& GROBLER, P. 2010. Risk equalisation and voluntary health insurance: The South Africa experience. Health Policy, 98:27-38.

MILLER, D. 1983. The correlates of entrepreneurship in three types of firms. Management Science, 29:770-791.

MINTZBERG, H. 2011. To fix health care, ask the right questions. Harvard Business Review, 44.

MONITOR GROUP LP. 2008. Health systems comparison project, commissioned by Discovery Health (Pty) Ltd 2008. Johannesburg: Discovery Health (Pty) Ltd.

MORRIS, M.H., KURATKO, D.F. \& COVIN, J.G. 2008. Corporate entrepreneurship and innovation, Mason OH, USA, South-Western Cengage Learning.

MORRIS, M.H. \& SEXTON, D.L. 1996. The concept of entrepreneurial intensity: Implications for company performance. Journal of Business Research, 36:5-13.

MUR-VEEMAN, I., EIJKELBERG, I. \& SPREEUWENBERG, C. 2001. How to manage the implementation shared care - a discussion of the role of power, culture and structure in the development of shared care arrangements. Journal of Management in Medicine, 15:142-155.

NELSON, R.R. 1991. Why do firms differ and how does it matter? Strategic Management Journal, 12:61-74. NONAKA, I. 1994. A dynamic theory of organizational knowledge creation. Organisation Science, 5:14-37. PÉREZ-LUÑO, A., WIKLUND, J. \& CABRERA, R.V. 2011. The dual nature of innovation activity: How entrepreneurial orientation influences innovation generation and adoption. Journal of Business Venturing, 26:555-571.

PODSAKOFF, P., MACKENZIE, S., LEE, J. \& PODSAKOFF, N. 2003. Common method biases in behavioral research: a critical review of the literature and recommended remedies. Journal of Applied Psychology, 88:879-903.

PORTER, M.E. \& TEISBERG, E. 2006. Redefining health care: creating value-based competition on results, Harvard Business School Press: Boston Massachusetts.

PROVAN, K.G. 1984. Interrogational cooperation and decision making autonomy in a consortium multihospital system. Academy of Management Review, 9:494-504.

RAUCH, A., WIKLUND, J., LUMPKIN, G.T. \& FRESE, M. 2004. Entrepreneurial orientation and business performance: Cumulative empirical evidence. 2004 Babson Colledge-Kauffman Foundation Entrepreneurship Research Conference.

ROSENBUSCH, N., BRINKMAN, J. \& BAUSCH, A. 2011. Is innovation always beneficial? A metaanalysis of the relationship between innovation and performance in SMEs. Journal of Business Venturing, 26:441-457.

SOININEN, J., MARTIKAINEN, M., PUUMALAINEN, K. \& KYLAHEIKO, K. 2011. Entrepreneurial orientation: Growth and profitability of Finnish small-and medium-sized enterprises. International Journal of Production Economics, Article in Press.

STOPFORD, J.M. \& BADEN-FULLER, C.W.F. 1994. Creating corporate entrepreneurship. Strategic Management Journal, 15:521-536.

STREMERSCH, S. 2008. Health and marketing: The emergence of a new field of research. International Journal of Research in Marketing, 25:229-233. 
SUHR, D. 2006. Exploratory or confirmatory factor analysis? Proceedings of the Thirty-first Annual SAS Users Group International Conference, 2006 Cary, NC. SAS Institute Inc, 5 January, 2012, www2.sas.com/proceedings/sugi31/200-31.pdf.

TEECE, D.J., PISANO, G. \& SHUEN, A. 1997. Dynamic capabilities and strategic management. Strategic Management Journal, 18:509-533.

TEISBERG, E.O. \& WALLACE, S. 2009. Creating a high-value delivery system for health care. Thoracic and Cardiovascular Surgery, 21:35-42.

URBAN, B. 2008. The prevalence of entrepreneurial orientation in a developing country: juxtapositions with firm success and South Africa's innovation index. Journal of Developmental Entrepreneurship, 13:425-443. URBAN, B. \& BARREIRA, J. 2010. Empirical investigations into firm technology orientation and entrepreneurial orientation. International Journal of Innovation and Technology Management, 7:329-351. VANVACTOR, J.D. 2011. Collaborative leadership model in the management of health care. Journal of Business Reserch, In press, Corrected proof.

WIKLUND, J 1999. The sustainability of the entrepreneurial orientation-performance relationship. Entrepreneurship Theory and Practice, 24:37-48.

WIKLUND, J. \& SHEPHERD, D.A. 2003. Knowledge-based resources, entrepreneurial orientation, and the performance of small and medium-sized businesses. Strategic Management Journal, 24:1307-1314.

WIKLUND, J. \& SHEPHERD, D.A. 2005. Entrepreneurial orientation and small business performance: A configurational approach. Journal of Business Venturing, 20:71-91.

ZAHRA, S.A. \& COVIN, J.G. 1995. Contextual influences on the corporate entrepreneurship-performance relationship: A longitudinal analysis. Journal of Business Venturing, 10:43-58.

ZAHRA, S.A. \& GARVIS, D.M. 2000. Entrepreneurship and firm performance: The moderating effect of international environmental hostility. Journal of Business Venturing, 15:469-492.

ZILLICH, A.J., DOUCHETTE, W.R., CARTER, B.L. \& KREITER, C.D. 2005. Development and initial validation of an instrument to measure physician-pharmacist collaboration from the physician perspective. Value in Health, 8:59-66. 